\title{
Community-acquired pneumonia guidelines: much guidance, but not much evidence
}

\author{
M. Woodhead
}

Community-acquired pneumonia (CAP) is changing. The emergence and spread of antibiotic resistance in common causative bacteria, the development of new microbiological diagnostic techniques, new understandings in the area of severity assessment and the development of new antibiotics are just some of the issues. Methods of guideline writing have also evolved [1]. The categorisation of evidence and the strength attributed to recommendations are perhaps the most important additions to this methodology [2]. Some aspects of the older guidelines for CAP management may therefore be out of date [3-5].

The publication of the British Thoracic Society (BTS) [6] and American Thoracic Society (ATS) Guidelines for the management of CAP [7] in 2001 and the Canadian [8, 9] and The Infectious Disease Society of North America (IDSA) Guidelines [10] in 2000 were most welcome. They all updated or revised earlier publications (after intervals of 8, 8, 7 and $2 \mathrm{yrs,}$ respectively) and attempted to take account of the issues mentioned above. The scope of each document is similar and they include issues such as clinical presentation and diagnosis, microbial and nonmicrobial investigation and general and antibiotic management. A separate publication confined to antibiotic recommendations was presented by the Centers for Disease Control and Prevention [11]. It is not the purpose of this paper to compare these documents item by item, but more to assess in general terms, their potential value and limitations and how and where they may or may not be used.

Guidelines are, whether we like it or not, part of current and future clinical practice. They may do good, but are costly to produce, have the potential to do harm and their close temporal proximity could cause confusion. How, then, should the potential guideline user evaluate them? Three questions are relevant. Is the guideline produced according to currently accepted methodological criteria? Is there any evidence that they work? Are they relevant?

A generic Appraisal Assessment tool is available to help determine whether guidelines have been developed using a rigorous and systematic approach [12]. This consists of a 37 -item questionnaire covering the

*Dept of Respiratory Medicine, Manchester Royal Infirmary, Manchester, UK

Correspondence: Dept of Respiratory Medicine, Manchester Royal Infirmary, Oxford Road, Manchester, M13 9WL, UK. Fax: 44 1612764989. E-mail: Woodhead@central.cmht.nwest.nhs.uk following three broad areas: Rigour of Development, Context and Content, and Application. Seven items in this questionnaire relate to evidence and recommendation grading, which should be part of all of these documents. The variation between documents is of interest. Recommendations were supported by "best level" evidence, however defined, in only $21 \%$ (IDSA Guideline: 52 graded recommendations [10]), 15\% (BTS: 95 recommendations [6]), 9.6\% (Canada: 31 graded recommendations [8, 9]), and 6.5\% (ATS: 61 graded recommendations [7]) of cases. This confirms that robust evidence is lacking for many of the important decisions made in patient management. The evidence that is available often does not state that intervention $\mathrm{A}$ is better than intervention $\mathrm{B}$. Judgement and consensus therefore remain important in the production of recommendations from this evidence. This is one reason perhaps, why despite the use of more or less the same reference base, the guidelines come to different conclusions over some issues.

Freedom from potential conflict of interest is therefore essential. Guidelines cost money. Guidelines should be written by those with expertise in the area in question. Such experts usually have associations at various levels with the pharmaceutical industry. Potential conflicts of interest are therefore difficult to assess. Such associations must at least be in the open and all guideline members should declare their interests [6, 11]. Funding of guideline production [7-9] from the pharmaceutical industry is undesirable, but must be acknowledged if no other means of funding is available.

Since the source evidence may be of poor quality, clinical studies that suggest that CAP guidelines are of benefit would be helpful. It should be remembered that a guideline contains many recommendations, some of which may make a difference while others may not. Some studies test a single intervention and others use critical pathways which combine a number of steps from a guideline. The fact that there is an overall benefit may not mean that all steps have an impact and, similarly, lack of benefit may not mean that all steps are ineffective. The ability of a change in practice, such as the application of a guideline, to make a difference depends on what was baseline normal practice. This was demonstrated in a study that found that guideline implementation failed to reduce length of hospital stay for CAP [13] and in two studies in which application of the pneumonia 
severity index would not have reduced the proportion admitted to hospital [13, 14]. The reasons for this may have been that initial length of stay was already shorter than usual [13] or that low-risk patients were admitted for reasons other than illness severity [14, 15]. Since baseline normal practice varies, the demonstration of benefit in one setting does not necessarily mean that the same effect can be predicted in another. The healthcare structure, frequency of causative pathogens, frequency of bacterial antibiotic resistance, availability of specific antibiotics and baseline practice levels are all examples of features that may show geographic variation. Recommendations for one country or region may not, therefore, be appropriate for all. The ATS guidelines may be useful in the USA and the British Guidelines in the UK, but neither may be helpful, and might even be harmful (e.g. by unnecessarily increasing costs [16]) in Sweden or Hungary, for example.

The apparently wide uptake of guideline recommendations [17] does not necessarily mean that outcomes will change [18]. Studies testing the impact of guidelines are difficult to conduct, few in number and have nearly all focused on aspects of North American Guidelines and have been performed on that continent. Some have adopted the before and after approach [13, 18-21], which may be confounded by secular changes in practice. Others have used a more rigorous methodology for control selection [22, 23]. The results are mixed and, to some extent, may reflect study design and setting. Reductions in hospital admission rates [19, 21, 22], length of hospital stay [20, 22], improvements in antibiotic management [19-22], oxygen assessment [20] and costs [21] have been shown. However, an initial admission reduction may be balanced by an increased rate of later admissions [19]. Only one study has suggested a mortality reduction following guideline implementation. However, only inpatient 30-day mortality was reduced with no change in either overall 30-day mortality or inpatient mortality [23]. A rise in postdischarge mortality, possibly as a result of a shortened hospital stay as a consequence of the guidelines, has been reported [24].

So, what can be concluded? Guideline methodology has improved, but the paucity of good evidence for many interventions in community-acquired pneumonia management remains a major limiting factor to their value. Studies on the impact of communityacquired pneumonia guidelines are at an early stage with many, but not all, showing benefits in the setting of each study. More widespread impact remains uncertain. The evidence gaps should now be a priority for research funding as should further studies on the impact of guideline implementation. The initial enthusiasm for community-acquired pneumonia guidelines persists but the relevance of published guidelines in different settings is unclear. Individual countries, or similar healthcare areas, should have their own guidelines relevant to that setting. This does not necessarily mean that the same development process has to be followed. It should be acceptable to modify those aspects of other appropriately developed guidelines to suit that individual setting.

\section{References}

1. Shekelle PG, Woolf SH, Eccles M, Grimshaw J. Clinical guidelines: developing guidelines. BMJ 1999; 318: 593-596.

2. Harbour R, Miller J. A new system for grading recommendations in evidence based guidelines. $B M J$ 2001; 323: 334-336.

3. British Thoracic Society. Guidelines for the management of community-acquired pneumonia in adults admitted to hospital. Br J Hosp Med 1993; 49: 346350.

4. American Thoracic Society. Guidelines for the initial management of adults with community-acquired pneumonia: diagnosis, assessment of severity, and initial antimicrobial therapy. Am Rev Respir Dis 1993; 148: $1418-1426$.

5. European study on community-acquired pneumonia committee. Guidelines for management of adult community-acquired lower respiratory tract infections. Eur Respir J 1998; 11: 986-991.

6. BTS Guidelines for the Management of Community Acquired Pneumonia in Adults. Thorax 2001; 56: Suppl. 4, IV1-64.

7. Niederman MS, Mandell LA, Anzueto A, et al. Guidelines for the management of adults with community-acquired pneumonia. Diagnosis, assessment of severity, antimicrobial therapy, and prevention. Am J Respir Crit Care Med 2001; 163: 1730-1754.

8. Mandell LA, Marrie TJ, Grossman RF, Chow AW, Hyland RH. Summary of Canadian guidelines for the initial management of community-acquired pneumonia: an evidence-based update by the Canadian Infectious Disease Society and the Canadian Thoracic Society. Can Respir J 2000; 7: 371-382.

9. Mandell LA, Marrie TJ, Grossman RF, Chow AW, Hyland RH. Canadian guidelines for the initial management of community-acquired pneumonia: an evidence-based update by the Canadian Infectious Diseases Society and the Canadian Thoracic Society. The Canadian Community-Acquired Pneumonia Working Group. Clin Infect Dis 2000; 31: 383-421.

10. Bartlett JG, Dowell SF, Mandell LA, File TM Jr, Musher DM, Fine MJ. Practice guidelines for the management of community-acquired pneumonia in adults. Infectious Diseases Society of America. Clin Infect Dis 2000; 31: 347-382.

11. Heffelfinger JD, Dowell SF, Jorgensen $\mathrm{JH}$, et al. Management of community-acquired pneumonia in the era of pneumococcal resistance: a report from the Drug-Resistant Streptococcus pneumoniae Therapeutic Working Group. Arch Intern Med 2000; 160: 1399 1408.

12. The AGREE Collaboration Appraisal of Guidelines for Research and Evaluation (AGREE). www. agreecollaboration.org. Date last accessed: May 25 2002.

13. Rhew DC, Riedinger MS, Sandhu M, Bowers C, Greengold N, Weingarten SR. A prospective, multicenter study of a pneumonia practice guideline. Chest 1998; 114: 115-119.

14. Marras TK, Gutierrez C, Chan CK. Applying a prediction rule to identify low-risk patients with community-acquired pneumonia. Chest 2000; 118: 1339-1343.

15. Stauble SP, Reichlin S, Dieterle T, Leimenstoll B, Schoenenberger R, Martina B. Community-acquired 
pneumonia-which patients are hospitalised? Swiss Med Wkly 2001; 131: 181-192.

16. Gleason PP, Kapoor WN, Stone RA, et al. Medical outcomes and antimicrobial costs with the use of the American Thoracic Society guidelines for outpatients with community-acquired pneumonia. JAMA 1997; 278: 32-39.

17. Woodhead M, Macfarlane J. Local antibiotic guidelines for adult community-acquired pneumonia (CAP): a survey of UK hospital practice in 1999. J Antimicrob Chemother 2000; 46: 141-143.

18. Hirani NA, Macfarlane JT. Impact of management guidelines on the outcome of severe community acquired pneumonia. Thorax 1997; 52: 17-21.

19. Atlas SJ, Benzer TI, Borowsky LH, et al. Safely increasing the proportion of patients with communityacquired pneumonia treated as outpatients: an interventional trial. Arch Intern Med 1998; 158: 1350-1356.

20. Meehan TP, Weingarten SR, Holmboe ES, et al. A statewide initiative to improve the care of hospitalized pneumonia patients: The Connecticut Pneumonia Pathway Project. Am J Med 2001; 111: 203-210.

21. Suchyta MR, Dean NC, Narus S, Hadlock CJ. Effects of a practice guideline for community-acquired pneumonia in an outpatient setting. Am J Med 2001; 110: 306-309.

22. Marrie TJ, Lau CY, Wheeler SL, Wong CJ, Vandervoort MK, Feagan BG. A controlled trial of a critical pathway for treatment of community-acquired pneumonia. CAPITAL Study Investigators. CommunityAcquired Pneumonia Intervention Trial Assessing Levofloxacin. JAMA 2000; 283: 749-755.

23. Dean NC, Silver MP, Bateman KA, James B, Hadlock CJ, Hale D. Decreased mortality after implementation of a treatment guideline for communityacquired pneumonia. Am J Med 2001; 110: 451-457.

24. Metersky ML, Tate JP, Fine MJ, Petrillo MK, Meehan TP. Temporal trends in outcomes of older patients with pneumonia. Arch Intern Med 2000; 160: 3385-3391. 